DOI: https://doi.org/10.53350/pjmhs2115103394

ORIGINAL ARTICLE

\title{
Teenage Pregnancy; Maternal and Fetal Outcomes
}

BUSHRA MEHMOOD ${ }^{1}$, ANISA SALEEM ${ }^{2}$, RUBINA KAUSAR ${ }^{3}$, AMNA ASLAM $^{4}$

${ }^{1}$ Assistant Professor Gynae \& Obs department, Shahida Islam Teaching Hospital, Lodhran,

${ }^{2}$ Senior Registrar Gynae \& Obs, HBS Medical and Dental College, Islamabad.

${ }^{3}$ Assistant Professor Gynae \& Obs, Avicena Medical and Dental College, Lahore.

${ }^{4}$ Assistant Professor Gynae \& Obs, Avicena Medical and Dental College, Lahore.

Correspondence to: Bushra Mehmood, Email; bushramehmood214@gmail.com, Cell: +92 3346058341

\begin{abstract}
Objective: The aim of this study is to determine the adverse adverse maternal and fetal outcomes in teenage pregnant women. Study Design: Randomized controlled trial

Place and Duration: Department of Gyne \& Obs, Shahida Islam Teaching Hospital Lodhran, during from 15-04-2020 to 31-032021.

Material and methods: Total one hundred and twenty patients were enrolled in this study. Patients were aged between $14-40$ years. Patients detailed demographics were recorded after taking written consent. Patients were equally divided into two groups I and II. 60 patients of aged between 14-18 years were included in group I and equally patients of aged $>18$ were included in group II. Frequency of pre-eclampsia, gestational diabetes mellitus and post-partum haemorrhage were calculated. Adverse outcomes among (cesarean section, instrumental delivery,induction of labor and prolong labor, hypertensive disorder) were calculated among both groups. Fetal outcomes Perinatal mortality, Low birth weight, Low Apgar score and NICU admission were observed. Complete data was analyzed by SPSS 22.0 version.

Results: Mean age of the patients in group I was $17.88 \pm 1.42$ years with mean BMI $22.09 \pm 4.66 \mathrm{Kg} / \mathrm{m}^{2}$ and in group II mean age was $19.16 \pm 8.64$ years with mean BMI $23.87 \pm 4.57 \mathrm{Kg} / \mathrm{m}^{2}$. Fetal outcomes, perinatal mortality in group I $8(13.3 \%)$ and in group II was 5 (8.3\%), low birth weight in group I was among 25 (41.7\%) and in group II was 9 (15\%), low apgar score in group I was 10 $(16.7 \%)$ and in group II was $7(11.7 \%), 12(20 \%)$ in group I went to NICU admission and $4(6.7 \%)$ patient in group II admitted to NICU. Frequency of pre-eclampsia in group I were high among 27 (45\%) patients as compared to group II $13(21.7 \%)$ patients , frequency of gestational diabetes mellitus in group I was among $14(23.3 \%)$ patients and $5(8.3 \%)$ patients were in group II, post partum haemorrhage was seen in $42(70 \%)$ cases in group I and $23(38.3 \%)$ cases in group II.

Conclusion: Delaying intrauterine development and premature neonatal intensive care admissions are also on the rise in this study. Anemia, urinary tract infection, high blood pressure pregnancy, and surgical delivery are all associated with pregnancies in which the mother is a teenager.
\end{abstract}

Keywords: Pre-eclampsia, Partum haemorrhage, Maternal outcome, Fetal outcome

\section{INTRODUCTION}

Adolescent girls between 15 and 19 years give birth to around 16 million babies each year, around $11 \%$ of births worldwide. Ninetyfive percent of these births occur in low- and middle-income countries, where complications from pregnancy and childbirth are a leading cause of death among girls of this age [1]. Although fertility rates in adolescents have declined since 1990, progress has slowed in this century, mainly in sub-Saharan Africa and Latin America, where about half and one third of women give birth before the age of 20 , respectively [2, 3].

Adolescent pregnancy has been a matter of concern, with unintended pregnancy, biological immaturity, insufficient prenatal care, inadequate maternal nutritional status, and stress all having an effect on neonatal and obstetric outcomes. Adolescent pregnancy and poorer pregnancy outcomes are linked by cultural, socioeconomic, social, and geographic factors. Abortion, severe anaemia, preterm birth, pre-eclampsia, operative and mechanical deliveries, and cephalo-pelvic imbalance are also correlated with teenage pregnancies.[4,5] Adolescent births are a global issue that affects countries of all income levels. Adolescent births are more frequent in disadvantaged populations globally, owing to poverty, poor education, and inadequate job opportunities.[6]Teenage mothers are also more likely than females of age group 20-24 years to develop eclampsia, systemic infections, puerperal endometritis, and live births to teenage mothers are more likely to have preterm delivery, low birth weight, and serious neonatal complications than newborn babies of females of age groups 2024 years.[6]Teenage expectant mothers can possibly not be as physically fit as a female in her 2nd decade of life to bear the financial strain of labour and pregnancy at such a young age. Adverse outcomes of adolescent pregnancy are caused by a variety of factors, including individual, socio-cultural, and familial factors, as well as inaccessibility to healthcare, contraceptives, and other services, which is the case in the majority of developed nations. Pregnancy associated complications, which may lead to maternal death, are more frequent among adolescent pregnant females because they are physically immature enough to satisfythe requirements of pregnancy.[7]

The World Health Organization (WHO) reported that the global adolescent pregnancy rate was $10.3 \%$ in 2014 , the highest rate was $28.8 \%$ in Nicaragua, whereas the lowest rate was $0.7 \%$ in Japan, an economically developed country [8]. In Bangladesh, with a low economic level in South Asia, the adolescent pregnancy rate in 2015 was $20.2 \%$ [9]. In Africa, adolescent pregnancy rate was $18.8 \%$ from 1990 to 2018 [10], and even more than $50 \%$ in subSaharan areas, with $44 \%$ of its population below 15 years old [11]. In rural Cameroon, the adolescent pregnancy rate was $20.4 \%$ from 2009 to 2016 [12]. In Ethiopia, Africa's second most populous country, the adolescent pregnancy rate was $13 \%$ in 2016 [13].

The goal was to evaluate the prevalence and the related maternal and perinatal outcome of adolescent pregnancies, which is predominantly rural. in this study.

\section{MATERIAL AND METHODS}

This randomized control trial was conducted at Department of Gyne \& Obs, Shahida Islam Teaching Hospital Lodhran, during from 15-04-2020 to 31-03-2021 and comprised of 120 patients. Patients detailed demographics were recorded after taking written consent. Patients with chronic illness and had $<26$ weeks of gestation were excluded from this study.

The women recruited were examined abdominally to determine the fetus' location, lie and presentation. Two transabdominal dimensions Ultrasound was performed to assess Age conception and fetal predictions weight, volume, placental amniotic fluid and exclude large fetal sites deficiencies. Patients were equally divided into two groups I and II. 60 patients of aged between 14-18 years were included in group I and equally patients of aged $>18$ were included in group II. Frequency of preeclampsia, gestational diabetes mellitus and post-partum haemorrhage were calculated. Adverse outcomes among (cesarean section, instrumental delivery,induction of labor and prolong labor, hypertensive disorder) were calculated among both 
groups. Fetal outcomes Perinatal mortality, Low birth weight, Low Apgar score and NICU admission were observed. Complete data was analyzed by SPSS 22.0 version.

\section{RESULTS}

Mean age of the patients in group I was $17.88 \pm 1.42$ years with mean BMI $22.09 \pm 4.66 \mathrm{Kg} / \mathrm{m}^{2}$ and in group II mean age was $19.16 \pm 8.64$ years with mean BMI $23.87 \pm 4.57 \mathrm{Kg} / \mathrm{m}^{2}$. Mean gestational age of group I was $36.17 \pm 5.17$ weeks while in group II mean gestational age was $35.23 \pm 7.49$ weeks. Mean parity ingroup I was $5.03 \pm 1.15$ while in group II it was $4.12 \pm 2.44$. (table1)

Table 1: Baseline detailed demographics of presented patients

\begin{tabular}{|l|c|l|}
\hline Variables & Group I & Group II \\
\hline Mean age (years) & $17.88 \pm 1.42$ & $19.16 \pm 8.64$ \\
\hline Mean BMI & $22.09 \pm 4.66$ & $23.87 \pm 4.57$ \\
\hline Gestational age (weeks) & $36.17 \pm 5.17$ & $35.23 \pm 7.49$ \\
\hline Mean Parity & $5.03 \pm 1.15$ & $4.12 \pm 2.44$ \\
\hline
\end{tabular}

Frequency of pre-eclampsia in group I were high among 27 (45\%) patients as compared to group II $13(21.7 \%)$ patients , frequency of gestational diabetes mellitus in group I was among 14 (23.3\%) patients and $5(8.3 \%)$ patients were in group II, post partum haemorrhage was seen in $42(70 \%)$ cases in group I and $23(38.3 \%)$ cases in group II. (table 2$)$

Table 2: Frequency of pre-eclampsia, Gestational Diabetes and Post PartumHaemorrhage among study cases

\begin{tabular}{|l|l|l|}
\hline Variables & Group I $(\mathrm{n}=60)$ & Group II $(\mathrm{n}=60)$ \\
\hline Pre-eclampsia & $27(45 \%)$ & $13(21.7 \%)$ \\
\hline Yes & $33(55 \%)$ & $47(78.3 \%)$ \\
\hline No & $14(23.3 \%)$ & $5(8.3 \%)$ \\
\hline Gestational Diabetes & $46(76.7 \%)$ & $55(91.7 \%)$ \\
\hline Yes & $42(70 \%)$ & $23(38.3 \%)$ \\
\hline No & $18(30 \%)$ & $37(61.7 \%)$ \\
\hline Post Partum Haemorrhage &
\end{tabular}

Frequency of maternal outcomes (cesarean section, instrumental delivery,induction of labor and prolong labor,) in group I were significantly higher than that of adult women. Fetal outcomes, perinatal mortality in group I $8(13.3 \%)$ and in group II was $5(8.3 \%)$, low birth weight in group I was among $25(41.7 \%)$ and in group II was 9 (15\%), low apgar score in group I was 10 $(16.7 \%)$ and in group II was 7 (11.7\%), $12(20 \%)$ in group I went to NICU admission and 4 (6.7\%) patient in group II admitted to NICU. (table 3)

Table 3: Frequency of maternal and fetal outcomes among both groups

\begin{tabular}{|l|l|l|}
\hline Variables & Group I & Group II \\
\hline Maternal Outcomes & $20(33.3 \%)$ & \\
\hline Cesarean section & $10(16.7 \%)$ & $3(16.7 \%)$ \\
\hline Instrumental delivery & $14(23.3 \%)$ & $4(6.7 \%)$ \\
\hline Induction of labor & $5(8.3 \%)$ & $3(5 \%)$ \\
\hline Prolong labor & & \\
\hline Fetal Outcomes & $8(13.3 \%)$ & $5(8.3 \%)$ \\
\hline Perinatal Mortality & $25(41.7 \%)$ & $9(15 \%)$ \\
\hline Low birth weight & $10(16.7 \%)$ & $7(11.7 \%)$ \\
\hline Low Apgar score & $12(20 \%)$ & $4(6.7 \%)$ \\
\hline NICU Admission & \multicolumn{2}{|l}{} \\
\hline
\end{tabular}

\section{DISCUSSION}

Maternal mortality and teenage morbidity are an important global public health concern. Natural vaginal delivery in mature moms was higher, but instrumental and optive CS in adolescent women were greater. There was no adequate prenatal therapy for a high majority of ladies in both classes. This may be because they are reluctant to seek medical advice (especially for teenagers) (particularly for teenagers). The refusal of pregnancy can also lead to delayed scheduling for teens. [14] Similar findings have been reported in other research which further show that young moms are a risk factor for preterm births. [15]

In our study total 120 cases were presented in which 60 patients in group I were aged between 14-18 years and 60 patients in group II were aged $>18$ years. Mean age of the patients in group I was $17.88 \pm 1.42$ years with mean BMI $22.09 \pm 4.66 \mathrm{Kg} / \mathrm{m}^{2}$ and in group II mean age was 19.16 \pm 8.64 years with mean BMI $23.87 \pm 4.57 \mathrm{Kg} / \mathrm{m}^{2}$. Our findings were comparable the previous studies.[16,17] Fetal outcomes, perinatal mortality in group I 8 $(13.3 \%)$ and in group II was $5(8.3 \%)$, low birth weight in group I was among $25(41.7 \%)$ and in group II was $9(15 \%)$, low apgar score in group I was 10 (16.7\%) and in group II was 7 (11.7\%), 12 $(20 \%)$ in group I went to NICU admission and $4(6.7 \%)$ patient in group II admitted to NICU. Frequency of pre-eclampsia in group I were high among 27 (45\%) patients as compared to group II 13 $(21.7 \%)$ patients , frequency of gestational diabetes mellitus in group I was among $14(23.3 \%)$ patients and $5(8.3 \%)$ patients were in group II, post partum haemorrhage was seen in $42(70 \%)$ cases in group I and $23(38.3 \%)$ cases in group II. Frequency of maternal outcomes (cesarean section, instrumental delivery, induction of labor and prolong labor,) in group I were significantly higher than that of adult women. These outcomes were similar to the previous many studies. [16-18]

Uncertainty abounds in regards to the function that attributes play in analysing unpleasant events experienced by mothers while their children were adolescents. As a result of socioeconomic variables such as low education levels, individual and insufficient prenatal care, the incidence of pregnancy-related complications is higher among young people [19]. As a result, poor prenatal care, low nutritional status, and a lack of parental participation among adolescents were all risk factors for bad pregnancy outcomes. In addition, de Vinne et al [20] discovered a link between insufficient prenatal care and pregnancy outcomes. The incidence of low apgar scores, asphyxiation, and low birth weight in teenagers is documented[21]." According to the study, the percentage of babies born underweight ranged from 5 percent to 28.7 percent [22].

Anemia, urinary tract inflammations, high blood pressure induced pregnancies, and surgery in young people are all associated with an increased chance of motherhood. Newborn mortality rates are on the rise, as is the risk of premature birth, low birth weight and frequent admission to neonatal treatment facilities.

\section{CONCLUSION}

Delaying intrauterine development and premature neonatal intensive care admissions are also on the rise in this study. Anemia, urinary tract infection, high blood pressure pregnancy, and surgical delivery are all associated with pregnancies in which the mother is a teenager.

\section{REFERENCE}

1. World Health Organization. World Health Statistics. 2013

2. United Nations. The Millennium Development Goal. Report. 2010

3. World Health Organization. Department of Child and Adolescent Health and Development. Adolescent pregnancy - Unmet needs and undone deeds. A review of the literature and programmes

4. Kingston D, Heaman M, Fell D, Chalmers B. Comparison of Adolescent, Young Adult and Adult Women's Maternity Experiences and Practices. Paediatrics J. 2012;129:1228-376

5. Aruda MM, Waddicor K, Frese L, Cole JC, Burke P. Early pregnancy in adolescents: diagnosis, assessment, options counseling, and referral. J Pediatr Health Care. 2010;24:4-13

6. Franjić S. Adolescent Pregnancy is a Serious Social Problem. J. Gynecol. Res. Obstet. 2018;4:006-8.

7. Paladugu RK, Donipudi PC, Chimata D, Jasti M. Adolescent pregnancy and its outcomes: a cross-sectional study. Int J Community Med Public Health. 2018;5(10):4408-14

8. Ganchimeg T, Ota E, Morisaki N, et al. Pregnancy and childbirth outcomes among adolescent mothers: a World Health Organization multicountry study. Bjog. 2014;121(Suppl 1):40-8

9. Nguyen PH, Sanghvi T, Tran LM, et al. The nutrition and health risks faced by pregnant adolescents: insights from a cross-sectional study in Bangladesh. PLoS One. 2017;12(6):e0178878. 
10. Kassa GM, Arowojolu AO, Odukogbe AA, et al. Prevalence and determinants of adolescent pregnancy in Africa: a systematic review and meta-analysis. Reprod Health. 2018;15(1):195-211.

11. Sama CB, Ngasa SN, Dzekem BS, et al. Prevalence, predictors and adverse outcomes of adolescent pregnancy in sub-Saharan Africa: a protocol of a systematic review. Syst Rev. 2017;6(1):247.

12. Agbor VN, Mbanga CM, Njim T. Adolescent deliveries in rural Cameroon: an 8-year trend, prevalence and adverse maternofoetal outcomes. Reprod Health. 2017;14(1):122.

13. Kassa GM, Arowojolu AO, Odukogbe AA, et al. Adverse neonatal outcomes of adolescent pregnancy in Northwest Ethiopia. PLoS One. 2019;14(6):e0218259

14. D. J. Murphy, "Epidemiology and environmental factors in preterm labour," Best Practice \& Research Clinical Obstetrics \& Gynaecology, vol. 21, no. 5, pp. 773-789, 2007.

15. C.-C. Lo, J.-J. Hsu, C.-C. Hsieh, T. T. Hsieh, and T.-H. Hung, "Risk factors for spontaneous preterm delivery before 34 weeks of gestation among Taiwanese women," Taiwanese Journal of Obstetrics and Gynecology, vol. 46, no. 4, pp. 389-394, 2007

16. Goossens G, Kadji C, Delvenne V. Teenage pregnancy: a psychopathological risk for mothers and babies? Psychiatr Danub. 2015 Sep;27 Suppl 1:S499-503. PubMed PMID: 26417827.
17. Abbas AM, Ali SS, Ali MK, Fouly H, Altraigey A. The maternal and neonatal outcomes of teenage pregnancy in a tertiary university hospital in Egypt. Proc Obstet Gynecol. 2017;7(3): Article 1 [ 10 p.]

18. Hadley A, Ingham R, Chandra-Mouli V. Implementing the United Kingdom's tenyear teenage pregnancy strategy for England (19992010): How was this done and what did it achieve? Reprod Health 2016 Nov 22;13(1):139.

19. Chandra-Mouli V, Camacho AV, Michaud PA. WHO guidelines on preventing early pregnancy and poor reproductive outcomes among adolescents in developing countries. J Adolesc Health. 2013 May;52(5):517-22.

20. A. P. Alio, A. K. Mbah, R. A. Grunsten, and H. M. Salihu, "Teenage pregnancy and the influence of paternal involvement on fetal outcomes," Journal of Pediatric and Adolescent Gynecology, vol. 24, no. 6, pp. 404-409, 2011.

21. C. M de Vinne, C. Creveuil, and M. Dreyfus, "Does young maternal age increase the risk of adverse obstetric, fetal and neonatal outcomes: a cohort study," European Journal of Obstetrics \& Gynecology and Reproductive Biology, vol. 147, no. 2, pp. 151-156, 2009.

22. M. Whitworth and R. Cockerill, "Antenatal management of teenage pregnancy," Obstetrics, Gynaecology \& Reproductive Medicine, vol. 20, no. 11 , pp. 323-328, 2010 